\title{
CONSIDERAÇÕES SOBRE O ESTÁGIO SUPERVISIONADO EM GEOGRAFIA
}

\author{
CONSIDERATIONS ABOUT THE SUPERVISED INTERNSHIP IN GEOGRAPHY
}

\section{Luana Caroline Kunast Polon}

RESUMO: O presente ensaio versa sobre algumas considerações acerca do Estágio Supervisionado nos cursos de Licenciatura em Geografia, tendo como base percepções constituídas a partir da experiência com orientações e supervisões de estagiários, bem como reflexões a partir de bases teóricas que discorrem sobre a relevância dos estágios no contexto de formação dos professores, em especial no âmbito da Geografia.

PALAVRAS-CHAVE: Geografia. Estágio supervisionado. Docência.

ABSTRACT: The present essay deals with some considerations about the Supervised Internship in the courses of graduation in Geography, based on the perceptions constituted from the experience with orientations and supervisions of trainees, as well as reflections from theoretical bases that discuss the relevance of the stages in the Context of teacher training, especially in the area of Geography.

KEYWORDS: Geography. Supervised internship. Teaching.

As práticas relativas ao Estágio Supervisionado nos cursos de Licenciatura podem variar consideravelmente conforme a estrutura curricular do curso em questão. No caso da Universidade Estadual do Oeste do Paraná, UNIOESTE, de Marechal Cândido Rondon, especificamente no curso de Licenciatura em Geografia, tem-se uma estrutura dividida em dois grandes momentos, atrelados às demais disciplinas que compõem a grade curricular. Os Estágios Supervisionados são efetivamente desenvolvidos no contexto do $3^{\circ}$ ano do curso no Ensino Fundamental, e no $4^{\circ}$ ano do curso no Ensino Médio. Como processo introdutório, tem-se já no $2^{\circ}$ ano da graduação uma primeira disciplina de Estágio Supervisionado, à qual introduz as práticas no processo formativo dos acadêmicos, por meio de atividades em sala de aula, criação de materiais didáticos, aperfeiçoamento de abordagens, etc.

Os Estágios Supervisionados são atualmente desenvolvidos basicamente da seguinte forma: escolha da escola e turma onde ocorrerá a regência (Ensino Fundamental primeiramente, excetuando-se o $6^{\circ}$ ano), confecção dos documentos burocráticos e apresentação do estagiário na escola, delimitação do tema da regência (em parceria com o professor responsável pela turma), orientação e supervisão desenvolvida por um docente da Universidade, acompanhamento do professor regente da turma e do professor da disciplina de Prática de Ensino do respectivo ano do curso em que o acadêmico se encontra, momentos de observação da escola e da sala de aula, elaboração dos planos de aula e textos paradidáticos, regência

Submetido em: 30/05/2017 - Aceito em: 22/06/2017 - Publicado em: 04/07/2017.

n. 2

p. $432-436$


efetivamente (sob supervisão parcial ou total do orientador e do professor da turma), elaboração do relatório final, devolutiva e protocolo do relatório.

O Estágio Supervisionado costuma ser um momento que gera ansiedades ao acadêmico, por ser, em sua ampla maioria, o primeiro contato deste com os alunos em sala de aula. No entanto, alguns graduandos já vivenciaram anteriormente esse contato, seja porque já estavam lecionando ou porque participam de projetos na Universidade como o PIBID (Programa Institucional de Bolsa de Iniciação à Docência). O momento do Estágio Supervisionado costuma produzir bons resultados e amadurecimento do acadêmico, o qual tem a oportunidade de concretizar na prática os conhecimentos e metodologias que são abordados em sala de aula no âmbito da graduação. Ainda assim, existem algumas questões que geram inquietação nos estagiários, como o fato de que pode ocorrer que os estagiários precisem ministrar um conteúdo que os mesmos ainda não estudaram de forma mais profunda na graduação. Além disso, muitos estagiários são bastante jovens quando desenvolvem os estágios, por vezes com idade igual ou pouco superior à de muitos alunos que encontrarão nas salas de aula. Não que isso seja um problema, mas gera algumas preocupações por parte dos estagiários.

A Geografia é uma importante disciplina no âmbito da constituição do pensamento crítico dos alunos. Neste sentido, o professor de Geografia:

[...] deverá permitir/estimular o aluno na sua capacidade de pesquisar, raciocinar, relacionar, argumentar, criar e aprender, superando a prática da cartilha e do exercício simples de memorização, sem negligenciar a importância dos conteúdos científicos sistematizados e sua apreensão como possiblidade emancipatória. Tratase de assumir o papel de formação do cidadão para a sociedade, preparando-o para ser sujeito, questionador e transformador de sua realidade (ABREU, 2012, p. 22).

Assim, além de ensinar os conteúdos específicos da disciplina, o professor deve ser capaz de instigar o aluno a pensar no contraditório, naquilo que não foi dito, refletir de forma consciente. Do mesmo modo, Vlach (2016, p. 09) analisa que a Geografia "é a disciplina que pode explicar às crianças e adolescentes os processos que levam a compreender porque a coexistência, contraditória e complementar, das lógicas territorial e das redes, agravou as desigualdades existentes". A complexidade da Geografia é, por vezes, um desafio ao acadêmico que ainda não vivenciou todos os conteúdos que perpassam o campo do conhecimento. Porém, é no Estágio Supervisionado que o acadêmico irá perceber quais os conteúdos escolares da Geografia e como recortá-los nas aulas, aprofundando conforme necessário e possível.

Os maiores receios dos estagiários residem nas formas pelas quais podem conseguir o respeito e a participação dos alunos em suas aulas, bem como nos melhores métodos avaliativos. Questões estas que são discutidas em conjunto com os professores regentes das 
turmas e os professores da Universidade. Os planos de aula são os elementos que norteiam a prática após as observações das aulas, podendo ser alterados caso seja necessário no decorrer dos estágios, uma vez que as turmas são dinâmicas e mudam seu comportamento em conformidade com o professor. Portanto, uma turma não será necessariamente igual com o professor regente e com o estagiário. Assim, há certa flexibilidade neste sentido.

Em termos práticos, os acadêmicos do curso e instituição analisados possuem a obrigatoriedade de cumprir um roteiro estabelecido a partir da documentação que norteia o Estágio Supervisionado no curso. Portanto, após serem preparados com as explicações teóricas e orientações em relação aos aspectos de conduta, os acadêmicos assistem cinco aulas nas salas nas quais realizarão seu estágio. Nesse momento, os acadêmicos entram em contato com o professor da turma, e começam a conhecer os alunos com os quais ele trabalhará. Da mesma forma, é o momento de conhecer a estrutura da escola, bem como a organização desta. Todo este momento é registrado nas "observações" do acadêmico, as quais serão entregues ao professor orientador.

Após realizadas as observações, bem como entregues dos planos de aula e os textos paradidáticos, enquanto recursos auxiliadores ao acadêmico, este recebe o aval de seu orientador para ingressar em sala de aula. O momento efetivo do Estágio Supervisionado é constituído pela regência de no mínimo doze aulas, acompanhadas pelo professor orientador e professor da turma em períodos específicos. O acadêmico geralmente fica apenas estas doze aulas em sala, havendo casos particulares de não finalização que podem estender o estágio para mais alguns dias. Os estagiários possuem condições de aplicar avaliações, corrigir atividades, utilizar metodologias de ensino e recursos que julgar relevantes, dentre outras atribuições em sala de aula.

Após o estágio, é construído o relatório final, o qual é a descrição e análise crítica da regência, o qual é desenvolvido pelo acadêmico conjuntamente com o professor orientador e supervisor. Esse documento reflete em parte as vivências do estagiário em sala, contendo ainda documentos relativos ao estágio, como os próprios planos de aula, textos paradidáticos e demais elementos fundamentais do estágio. Ao término, é realizado ainda um momento de devolutiva com toda a turma, onde os estagiários podem falar sobre sua experiência, mostrando os pontos positivos e negativos, as dificuldades e os benefícios do estágio na formação acadêmica. Os Estágios Supervisionados no âmbito do curso de Licenciatura em Geografia da Unioeste de Marechal Cândido Rondon são obrigatórios, e constituem-se parte fundamental da formação dos professores de Geografia, uma vez que é no estágio onde os acadêmicos viverão, ainda que parcialmente, a realidade de uma escola e de uma sala de aula. Sendo um momento, por vezes, decisivo na vida profissional do professor em formação.

Pode-se dizer que o Estágio Supervisionado é um dos momentos mais importantes no contexto da formação de professores, uma vez que se constitui na ocasião de colocar

\begin{tabular}{l|l|l|l|l|l|} 
Rev. Inter. Educ. Sup. & Campinas, SP & v.3 & n.2 & p.432-436 & maio/ago. 2017 \\
\hline
\end{tabular}


efetivamente em prática os conhecimentos específicos adquiridos por meio das disciplinas do curso em conjunto com os conhecimentos da Didática, percebendo quais os melhores métodos para trabalhar com os conteúdos, bem como as formas pelas quais se estabelece o relacionamento produtivo entre alunos e professores. Assim, ainda que sejam apenas algumas aulas efetivamente, o Estágio Supervisionado pode ser considerado fundamental para a adequada formação dos Licenciados em Geografia, devido ao processo amplo em que está envolvido o estágio, não se limitando apenas à regência em si, mas todo complexo de preparação e vivências.

Os conhecimentos teóricos obtidos a partir das várias disciplinas no contexto da graduação em Geografia são essenciais para constituição do arcabouço teórico do futuro profissional, no entanto, é no contexto do Estágio Supervisionado que o acadêmico irá entrar em contato com os aspectos indispensáveis para a constituição da sua identidade docente, bem como com os saberes cotidianos na profissão. Assim, para Pimenta; Lima (2004) o estágio é o eixo central da formação dos professores. É no momento do estágio que muitos acadêmicos efetivamente percebem se querem ou não seguir a carreira docente, o que acaba também ocasionando alguma evasão dos cursos de Licenciatura nesse período, pois nem todos sentem-se confortáveis em vivenciar a experiência.

Aos professores que recebem os estagiários, a experiência também pode ser um processo enriquecedor, de modo que os acadêmicos chegam com muitas novidades e vontade de aplicar conhecimentos e técnicas. Assim, conforme analisado por Pimenta; Lima (2004), os professores das turmas que recebem estagiários têm condições de entrar em contato com práticas inovadoras e atividades diferentes daquelas que ele aprendeu ou conhece. Essa troca de conhecimentos e experiências pode motivar sua prática, bem como melhorar sua didática em sala de aula. Neste sentido, o desafio que surge é a compreensão dos motivos que levam os professores já experientes a deixarem, em algumas ocasiões, os aspectos mais didáticos e dinâmicos de suas aulas em detrimento de uma abordagem mais teórica com o passar dos anos. E neste sentido, cabe um incentivo aos estagiários para que repensem constantemente suas abordagens, evitando deixar que sua prática caia no comodismo e deixe de ser tão atraente ao aluno como se apresenta no momento do Estágio Supervisionado.

Após a finalização do Estágio Supervisionado, tanto no Ensino Fundamental, quanto no Ensino Médio, há um momento de reflexão conjunta entre acadêmicos e orientadores no âmbito da Universidade. Neste momento, os alunos têm a oportunidade de falar sobre suas experiências, compartilhando com os colegas suas dificuldades e os bons momentos vividos. Neste encontro, é comum que ocorra uma emoção muito grande por parte dos estagiários, de um lado pelo sentimento de superação desta etapa de sua formação, de outro por relembrarem das dificuldades que passaram no decorrer do processo, como a distância que precisaram percorrer para chegar às escolas, os medos que tiveram que superar, as dúvidas e conflitos internos em relação à docência, dentre outros. É a devolutiva que fecha, pelo menos neste 
momento, a experiência do Estágio Supervisionado no contexto do curso de Licenciatura em Geografia da UNIOESTE de Marechal Cândido Rondon.

\section{REFERÊNCIAS}

ABREU, Silvana de. Formação do professor de Geografia: construindo conhecimento, consolidando práticas; aspectos da relação ensino-aprendizagem. In: ANDRES, Juliano; FRANCISCHETT, Mafalda Nesi; AGUIAR, Waldiney Gomes de (Org.). Ensino de Geografia: abordagens sobre representações geocartográficas e formação do professor. Cascavel: EDUNIOESTE, 2012. p.11-48.

PIMENTA, Selma Garrido; LIMA, Maria Socorro Lucena. Estágio e docência. 2 Ed. São Paulo: Cortez, 2004.

VLACH, Vânia Rubia Farias. Ensino de Geografia no início do século XXI: desafios e perspectivas. Disponível em: $\lfloor$ http://observatoriogeograficoamericalatina.org.mx/egal9/ Teoriaymetodo/Teoricos/04.pdf>. Acesso em: 15 Ago. 2016.

\section{${ }^{\mathrm{i}}$ Sobre a autora}

\section{Luana Caroline Kunast Polon}

E-mail: luanacaroline.geografia@ gmail.com / ORCID: http://orcid.org/0000-0001-9139-2502 Universidade Federal da Fronteira Sul - Brasil

Mestra em Geografia pela Universidade Estadual do Oeste do Paraná [UNIOESTE]. 